\title{
Plant and System Operators
}

National Cancer Institute

\section{Source}

National Cancer Institute. Plant and System Operators. NCI Thesaurus. Code C122498.

The group of professions that include chemical plant system operators, nuclear power reactor operators, power distributors and dispatchers, power plant operators, water and wastewater treatment plant and system operators, stationary engineers and boiler operators, and gas plant operators, petroleum pump system operators, refinery operators, and gaugers. 